Josephine Ann P. Ramos, MD

Frederick Mars B. Untalan, MD

Department of Otorhinolaryngology

Head and Neck Surgery

Baguio General Hospital and Medical Center
Correspondence: Dr. Frederick Mars B. Untalan

Department of Otorhinolaryngology

Head and Neck Surgery

Baguio General Hospital and Medical Center

1 Governor Pack road, Baguio City, Benguet 2600

Philippines

Phone: (+63) 9175066551

E-mail: tongmd@yahoo.com

The authors declared that this represents original materia that is not being considered for publication or has not been published or accepted for publication elsewhere in full or in part, in print or electronic media; that the requirements for authorship have been met by all the authors, and that each author believes that the manuscript represents honest work.

Disclosures: The authors signed a disclosure that there are no financial or other (including personal) relationships, intellectual passion, political or religious beliefs, and institutional affiliations that might lead to a conflict of interest.

Presented at the Philippine Society of Otolaryngology Head and Neck Surgery Descriptive Research Contest (2nd Place) December 6, 2019. Palawan Ballroom, Edsa Shangri La Hotel, Mandaluyong City.

\section{Effectiveness of the Philippine Health Insurance Corporation Case Rate System for Thyroidectomy in a Tertiary Government Hospital}

\begin{abstract}
Objective: To determine the effectiveness of the Philippine Health Insurance Corporation (PhilHealth) case rate system in reducing out-of-pocket expenses among non-no balance billing (NBB) patients undergoing thyroidectomy under the Department of Otorhinolaryngology Head and Neck Surgery of the Baguio General Hospital and Medical Center from February to September 2018.
\end{abstract}

\section{Methods:}

\section{Design: Prospective Cross- Sectional \\ Setting: $\quad$ Tertiary Government Hospital}

Participants: Sixty-four (64) randomly selected patients with PhilHealth who underwent thyroidectomy who agreed to participate and reveal their statements of accounts

Results: Among the study population, $20 \%$ belonged to the no balance billing (NBB) category, with zero out-of-pocket expenses during their confinement. Eighty percent (80\%) belonged to the non-NBB category and also incurred zero hospital charges. In addition, there was no significant difference in the individual categories of the hospital expenses between the two groups except for the surgical procedures $(p=.018,95 \% \mathrm{Cl})$. The accumulated total expenses also did not significantly differ between the two groups $(p=.063,95 \% \mathrm{Cl})$. The minimum amount billed was PhP 1,984.95, while the maximum amount charged was PhP 38,898.65, with a median of PhP 18,703.28 and interquartile range of PhP 4,251.78 ( $X_{U}:$ PhP 20,848.74, $X_{L}:$ PhP 16,596.96). There were no reported out-of-pocket expenses from non-NBB patients. The actual cost of thyroidectomy did not differ significantly from the case rate provided by PhilHealth among all the RVS categories.

Conclusion: The PhilHealth case rate system is effective in reducing out-of-pocket expenses among non-NBB patients who underwent thyroidectomy in our institution during the study period.

Keywords: out-of-pocket expenses; thyroidectomy; health care financing; health expenditures: universal health coverage 


\section{ORIGINAL ARTICLES}

The creation of the Philippine Health Agenda in 2016 has reemphasized the need for accessible health care through a universal health insurance.' The Philippine Health Insurance Corporation (PhilHealth) was seen as the gateway to free affordable care using No Balance Billing (NBB) for the poor or basic accommodation and fixed co- payment for non- basic accommodation. ${ }^{2}$ The NBB policy provides that no other fees or expenses shall be charged or paid for by indigent patients above and beyond the packaged rates during their confinement period. ${ }^{3}$ The limited depth and breadth of coverage, however, has resulted in high levels of out-of-pocket payments, which continue to rise despite the enormous programmatic and policy reforms in the health financing system.

This problem has been observed in our local setting. Among the 600 patients who underwent surgery in the Department of Otorhinolaryngology- Head and Neck Surgery during the previous year, a significant percentage of non-NBB patients was noted to have large out-of-pocket expenses for a myriad of reasons. These unnecessary expenses can be highly catastrophic and impoverishing. Patients were noted to have a higher risk to forgo care, delay health seeking and become non- compliant.

This study aims to determine the effectiveness of the PhilHealth case rate system in reducing out-of-pocket expenses among nonNBB patients undergoing thyroidectomy. This may be used to create a standardized process by which hospital charges can be based. Once standardized, process defects, as well as processing time will be reduced. Policies can be created to reduce out-of-pocket expenses to rational levels. Strategies may be identified to expand PhilHealth benefits to cover a broader range of services. These can help make health care more equitable, inclusive, transparent and accountable in line with the Philippine Health Agenda for 2016- 2022.

\section{METHODS}

This is a prospective cross-sectional study carried out in a tertiary public hospital. The population was composed of the statements of accounts of public (charity) patients who underwent thyroidectomy from February to September 2018.

The charts of patients that were included in the study must have fulfilled the following criteria: (1) must have PhilHealth listed as the health insurance; (2) must indicate that the patient underwent any of the following types of thyroidectomy: (a) partial thyroid lobectomy, unilateral, with or without isthmusectomy (RVS: 60210), (b) partial thyroid lobectomy, unilateral, with contralateral subtotal lobectomy, including isthmusectomy (RVS:60212), (c) total thyroid lobectomy, unilateral, with or without isthmusectomy (RVS: 60220), (d) total thyroid lobectomy, unilateral, with contralateral subtotal lobectomy, including isthmusectomy (RVS: 60225), (e) thyroidectomy, total or complete (RVS: 60240), (f) thyroidectomy, removal of all remaining thyroid tissue following previous removal of thyroid (RVS: 60260) or (g) thyroidectomy, total or subtotal for malignancy, with limited neck dissection (RVS: 60252). The following exclusion criteria were applied: (1) use of other health insurances aside from PhilHealth; (2) presence of other co-morbid conditions in the final diagnosis; (3) more complicated types of thyroidectomy, including the following: (a) thyroidectomy, total or subtotal for malignancy, with radical neck dissection (RVS: 60254), (b) thyroidectomy, including substernal thyroid gland; sternal split or transthoracic approach (RVS: 60270) or (c) thyroidectomy, including substernal thyroid gland; cervical approach (RVS: 60271); and (4) incomplete charts.

We limited the study to 64 billing statements which was computed using the prevalence of patients that underwent thyroidectomy for the year $2016(\mathrm{~N}=76)$, a confidence interval of 95\%, a margin of error of 5\% and a power of $80 \%$. The billing statements were selected using a table of random numbers.

After obtaining approval from the Institutional Technical Review Board and Research Ethics Committee, informed consent was obtained from the participants. Upon admission, data such as employment (unemployed/ contractual/ self- employed/ employed), salary in Philippine Pesos (PhP) per month (no fixed income/ less than PhP 10,000/ PhP 10,000 - 19,999, PhP 20,000 - 29,999, PhP 30,000 and above), PhilHealth membership classification (employed/ individually paying/ overseas Filipino worker/sponsored/ indigent/ lifetime/ senior citizen) and billing classification (NBB/ non-NBB), were obtained using a questionnaire. On the day of the patient's discharge, the procedure performed (i.e., type of thyroidectomy) and statement of account were obtained, including particular expenses (room and board, drugs and medicine, supplies, radiology, laboratory and ancillary procedures, use of the operating room, and surgical procedures) and any out- of- pocket payments.

Descriptive statistics were calculated including the comparison of the cost of hospitalization and the PhilHealth case rate. Descriptive summary measures for continuous variables were presented in terms of mean \pm standard deviation or median and interquartile ranges; and for categorical variables, summaries were presented in frequency counts and proportions. Comparisons between the cost of hospitalization among NBB and non-NBB patients and associations of the items included in the PhilHealth case rate and actual cost of thyroidectomy utilized the independent t-test. All data were encoded in Microsoft Excel for Mac 2011 Version 14.4.0 (Microsoft Corporation, Redmond, 
WA, USA). Statistical analysis was performed using IBM SPSS Statistics for Windows Version 20.0 (IBM Corp., Armonk, NY, USA). All hypotheses tests used a 0.05 a- level of significance.

\section{RESULTS}

A total of 64 patients met the inclusion criteria and consented to participate in the study. The profile of the participants based on the employment status, monthly income, PhilHealth membership classification, billing classification and procedure performed is presented in Table 1.

The comparison of the average cost of hospitalization between NBB and non-NBB patients indicate that there was no significant difference in the individual categories of hospital expenses, except for the surgical procedures $(p=.018,95 \% \mathrm{Cl})$. The accumulated total expenses also did not differ significantly between the two groups $(p=.063,95 \% \mathrm{Cl})$ as shown below in Table 2.

The minimum amount billed was PhP 1,984.95 while the maximum amount charged was PhP 38,898.65 with a median of PhP 18,703.28 and interquartile range of $\mathrm{PhP} 4,251.78\left(\mathrm{X}_{\mathrm{U}}\right.$ : $\mathrm{PhP}$ 20,848.74, $\mathrm{X}_{\mathrm{L}}$ : PhP $16,596.96)$. There were no reported out-of-pocket expenses from nonNBB patients.

The comparison of the average actual cost of thyroidectomy and the PhilHealth case rate is also shown in Table 3.

Based on the average cost of thyroidectomy procedures, RVS 60225 (total thyroid lobectomy, unilateral, with contralateral subtotal lobectomy including isthmusectomy) had the highest average cost at PhP 21,556.30 while RVS 60220 (total thyroid lobectomy, unilateral, with or without isthmusectomy) had the lowest value at PhP 16,282.12. The actual cost of thyroidectomy did not differ significantly from the case rate provided by PhilHealth among all the RVS categories.

\section{DISCUSSION}

The Philippine Health Agenda was launched to achieve universal health care for all Filipinos through the achievement of three health system goals. ${ }^{1}$ Among these, financial risk protection through the national health insurance program (NHIP) is PhilHealth's primary responsibility. ${ }^{4}$ This aims to protect Filipinos especially the marginally poor against the catastrophic cost of illness. Through the NHIP, resources need to be generated to improve the provision of public health services to consequently achieve the Millennium Development Goals. $^{5}$

Health insurance coverage is measured at the individual level to include both public insurance (though PhilHealth) and private insurance
Table 1. Clinico- demographic profile of patients who underwent thyroidectomy at the Baguio General Hospital and Medical Center from February to September 2018

\begin{tabular}{|c|c|c|c|c|}
\hline & \multicolumn{2}{|c|}{ FREQUENCY } & \multicolumn{2}{|c|}{ PROPORTION (\% } \\
\hline \multicolumn{5}{|l|}{ EMPLOYMENT } \\
\hline Unemployed & 35 & \multirow{4}{*}{$=64$} & 54.7 & \multirow{4}{*}{$=100$} \\
\hline Contractual & 0 & & 00.0 & \\
\hline Self- Employed & 25 & & 39.1 & \\
\hline Employed & 4 & & 06.3 & \\
\hline
\end{tabular}

\section{MONTHLY SALARY}

\begin{tabular}{|c|c|c|c|}
\hline No Fixed Income & 31 & \multirow{5}{*}{$=64$} & 48.4 \\
\hline$<$ PHP10,000 & 11 & & 17.2 \\
\hline PHP 10,000 - 19,999 & 20 & & 31.3 \\
\hline PHP 20,000 - 29,999 & 2 & & 03.1 \\
\hline$\geq$ PHP 30,000 & 0 & & 00.0 \\
\hline
\end{tabular}

\section{PHILHEALTH MEMBERSHIP CLASSIFICATION}

\begin{tabular}{|c|c|c|c|}
\hline Employed & 7 & \multirow{7}{*}{$=64$} & 10.9 \\
\hline Individually Paying & 35 & & 54.7 \\
\hline OFW & 0 & & 00.0 \\
\hline Sponsored & 2 & & 03.1 \\
\hline Indigent & 13 & & 20.3 \\
\hline Lifetime & 0 & & 00.0 \\
\hline Senior Citizen & 7 & & 10.9 \\
\hline
\end{tabular}

BILLING CLASSIFICATION

\begin{tabular}{|l|l|l|l|l|}
\hline NBB & 13 & \multirow{2}{*}{$=64$} & 20.3 & \multirow{2}{*}{$=100$} \\
\cline { 1 - 2 } Non- NBB & 51 & & 79.7 & \\
\cline { 1 - 2 } PROCEDURE PERFORMED & &
\end{tabular}

PROCEDURE PERFORMED

RVS 60210

Partial Thyroid Lobectomy, Unilateral with or without Isthmusectomy

\section{RVS:60212}

Partial Thyroid Lobectomy,

Unilateral, with contralateral subtotal lobectomy, Including Isthmusectomy RVS: 60220

Total Thyroid Lobectomy, Unilateral, with or without isthmusectomy RVS: 60225

Total Thyroid Lobectomy, Unilateral, with contralateral subtotal lobectomy, Including Isthmusectomy RVS: 60240

Thyroidectomy, Total or Complete RVS: 60260

Thyroidectomy, Removal of all Remaining Thyroid Tissue following previous removal of thyroid

RVS: 60252

Thyroidectomy, Total or Subtotal for Malignancy, with Limited Neck Dissection

\begin{tabular}{|c|c|c|c|}
\hline 4 & $=64$ & 06.3 & $=100$ \\
\hline 0 & & 00.0 & \\
\hline 14 & & 21.9 & \\
\hline 2 & & 03.1 & \\
\hline 25 & & 39.1 & \\
\hline 14 & & 21.9 & \\
\hline 5 & & 07.8 & \\
\hline
\end{tabular}


Table 2. Comparison of the average cost of hospitalization between NBB and non-NBB patients undergoing thyroidectomy

\begin{tabular}{|l|c|c|c|}
\multicolumn{1}{|c|}{ PARTICULARS } & $\begin{array}{c}\text { NBB in PhP } \\
\text { (N=51) }\end{array}$ & $\begin{array}{c}\text { NON-NBB } \\
\text { in PhP (N=13) }\end{array}$ & P-VALUE \\
\hline Professional Fee & 0.00 & 0.00 & .000 \\
\hline Surgical Procedures & $2,176.97$ & $2,576.63$ & .018 \\
\hline Use of Operating Room & $4,661.96$ & $4,569.23$ & .415 \\
\hline $\begin{array}{l}\text { Radiology, Laboratory } \\
\text { and Other Ancillary } \\
\text { Procedures/ Clinical } \\
\text { Laboratory Expenses }\end{array}$ & 545.76 & 786.08 & .434 \\
\hline Medical Supplies & $1,273.73$ & $1,522.83$ & .165 \\
\hline Drugs and Medicine & $2,138.92$ & $2,002.74$ & .113 \\
\hline Room and Board & $1,769.23$ & $1,879.69$ & .169 \\
\hline $\begin{array}{l}\text { ACCUMULATED } \\
\text { TOTAL EXPENSES }\end{array}$ & $\mathbf{1 2 , 5 5 6 . 5 7}$ & $\mathbf{1 3 , 3 3 7 . 2 0}$ & $\mathbf{. 0 6 3}$ \\
\hline
\end{tabular}

Table 3. Comparison of the actual cost of thyroidectomy and PhilHealth case rate

\begin{tabular}{|l|c|c|c|} 
& $\begin{array}{c}\text { AVERAGE ACTUAL COST } \\
\text { OF THYROIDECTOMY } \\
\text { (PhP) }\end{array}$ & $\begin{array}{c}\text { CASE RATE } \\
\text { FROM PHIC (PhP) }\end{array}$ & P-VALUE \\
\hline RVS 60210* & $18,660.85$ & $31,000.00$ & .210 \\
\hline RVS 60220+ & $16,282.12$ & $31,000.00$ & .212 \\
\hline RVS 60225 & $21,556.30$ & $31,000.00$ & .208 \\
\hline RVS 60240§ & $19,857.07$ & $31,000.00$ & .210 \\
\hline RVS 602601 & $21,200.26$ & $31,000.00$ & .203 \\
\hline RVS 60252\# & $20,800.98$ & $31,000.00$ & .209 \\
\hline
\end{tabular}

"Partial thyroid lobectomy, unilateral, with or without isthmusectomy.

${ }^{+}$Total thyroid lobectomy, unilateral, with or without isthmusectomy.

${ }^{\text {}}$ Total thyroid lobectomy, unilateral, with contralateral subtotal lobectomy, including isthmusectomy.

sThyroidectomy, total or complete.

"Thyroidectomy, removal of all remaining thyroid tissue following previous removal of thyroid.

"Thyroidectomy, total or subtotal for malignancy, with limited neck dissection.

(through private health maintenance organizations (HMOs). ${ }^{6}$ Out-ofpocket health expenditure is defined as direct purchases by households of health services or goods, like medicines, hospital room charges, consultation fees and diagnostic tests. It excludes dental charges, food supplements, various alternative therapies and transportation for medical care. ${ }^{6}$ Purchasing of health services is particularly relevant in the thrust of financial risk protection. ${ }^{5}$ The focus of social health insurance in the Philippines has long been on expanding membership, but as coverage approached 80-90 percent of the population, this has shifted to increasing the reimbursement rate (or the so-called "support value"). Through this, health insurance indeed reduced a household's probability of falling into poverty due to a member's illness. ${ }^{7}$ Along with the introduction of case payment is the introduction of the No Balance Billing (NBB) policy, which provides that no other fees or expenses shall be charged or be paid for by indigent patients above and beyond the packaged rates during their confinement period. ${ }^{3}$

Among the patients who underwent thyroidectomy from February to September 2018, 20\% belonged to the NBB category with zero out-of-pocket expenses during their confinement. Eighty percent $(80 \%)$ belonged to the non- NBB category which also incurred zero hospital charges. The average cost of hospitalization did not differ significantly between the NBB and non- NBB patients. This, however, seems to contradict the fact that patients still complain of the high cost of out-of-pocket expenses in the outpatient department especially for laboratories, clearances and medications prior to their surgery. The compensation provided for by the PhilHealth case rate for thyroidectomy covers only the expenses during the patient's confinement. It excludes those incurred during the patient's consult in the outpatient department. The current setup for patients scheduled for thyroidectomy is to perform all diagnostic workups on an outpatient basis. These include but are not limited to neck ultrasound, thyroid function tests (FT4, TSH), fine needle aspiration biopsy (FNAB), complete blood count (CBC), urinalysis (UA), 12-lead electroardiogram (ECG) and chest $\mathrm{x}$-ray. Should there be any derangement in the patient's laboratory results that would warrant treatment, the patients are prescribed medications and are advised to have their laboratory tests repeated at the out-patient department (OPD) on follow- up. A patient who needs to undergo treatment for abnormalities in thyroid function (i.e., hyperthyroidism or hypothyroidism) for instance, would need to take medications daily for 2-6 weeks before a repeat laboratory testing could be done. Such expenditures were therefore not considered "outof-pocket expenses" in this study since they were incurred prior to the patient's confinement.

Despite a uniform case rate for simple thyroidectomy cases, there exists a wide standard deviation in the hospital bill charged ranging from PhP 1, 984.95 to PhP 38, 898.65. Variations in charges commonly came from procedures, drugs and medicine, and operating room supplies like oxygen, which could be caused by the lack of a uniform system of charging in the materials used. Each particular expenditure category (i.e., room and board, drugs and medicines, supplies, radiology, laboratory and ancillary procedures, use of the operating room, and surgical procedures) could not be compared to a standard, since the given PhilHealth case rate does not include a breakdown of its coverage. Nevertheless, the case rate provided by PhilHealth for all RVS cases used in this study is effective in terms of reducing the out-ofpocket expenses among non-NBB patients during their confinement.

Our study limitations include design bias, since it did not account for all of the expenses incurred for thyroidectomy particularly the out-of-pocket expenses in the out- patient department. The lack of a 


\section{ORIGINAL ARTICLES}

standard by which expenditure categories could be compared to also pose another limitation. It is therefore our recommendation to include all outpatient expenses in the case rate coverage to reduce the outof-pocket expenditures further. There should also be a standardized system of charging of supplies used to maximize the case rate, probably through the use of OR packages for thyroidectomy. Further studies are also encouraged to determine if the PhilHealth case rate is effective for private patients undergoing thyroidectomy and for other conditions or procedures.

In conclusion, the PhilHealth case rate system is effective in reducing out-of-pocket expenses among non-NBB patients who underwent thyroidectomy in our institution from February to September 2018.

\section{ACKNOWLEDGEMENTS}

We would like to thank Dr. Mary Jane T. Lubos for her supervision in editing the manuscript, and Mr. Emmanuel J. Bacud for his assistance in statistical analysis.

\section{REFERENCES}

1. Romualdez AJ Jr., Rosa JFED, Flavier JDA, Quimbo SLA, Hartigan-Go KY, Lagrada LP, et al. The Philippines health system review [Internet]. The Philippines health system review. Health Systems in Transition; 2011 [cited 2017 May 18]; 1(2): Available from: http://www.wpro.who.int/ philippines/areas/health_systems/financing/philippines_health_system_review.pdf.

2. Cabral El. Department of Health. All for health towards health for all: Philippine Health Agenda 2016-2022 [Internet]. Manila (Philippines): Department of Health; 2016 [ cited 2017 May 16]; 54(2) : Available from: https://www.doh.gov.ph/sites/default/files/basicpage/Philippine\%20 Health\%20Agenda_Dec1_1.pdf.

3. Philippine Health Insurance Corporation. PhilHealth Members [Internet]. Manila (Philippines): Philippine Helath Insurance Corporation; 2014 [cited 2017 May 16]. Available from: https:// www.philhealth.gov.ph/members.

4. Department of Health. The Philippine health situation at a glance [Internet]. Manila (Philippines): Department of Health; 2015 [cited 2017 May 16]. Available from: https://www. doh.gov.ph/sites/default/files/basic-page/chapter-one.pdf.

5. Picazo OF, Ulep VGT, Pantig IM, Ho BL. A Critical Analysis of Purchasing of Health Services in the Philippines: A Case Study of PhilHealth [Internet]. PIDS Discussion Paper Series; 2015 Dec [cited 2017 May 21]. Available from: https://dirp3.pids.gov.ph/websitecms/CDN/PUBLICATIONS/ pidsdps1554.pdf.

6. Bredenkamp C, Buisman LR. Financial protection from health spending in the Philippines: policies and progress. Health Policy Plan. 2016 Sep; 31(7): 919-27. DOI: 10.1093/heapol/czw011 PMID: 27072948

7. Obermann $\mathrm{K}$, Jowett $\mathrm{M}$, Kwon $\mathrm{S}$. The role of national health insurance for achieving UHC in the Philippines: a mixed methods analysis. Glob Health Action. 2018;11(1):1483638. DOI: 10.1080/16549716.2018.1483638; PMID: 29914319; PMCID: PMC6008596. 